\title{
Forced Response of Polar Orthotropic Tapered Circular Plates Resting on Elastic Foundation
}

\author{
A. H. Ansari \\ Department of Mathematics, AlBaha University, Al Baha 1988, Saudi Arabia \\ Correspondence should be addressed to A. H. Ansari; ansaridranwar@rediffmail.com
}

Received 10 April 2016; Accepted 9 June 2016

Academic Editor: Mohammad Tawfik

Copyright (C) 2016 A. H. Ansari. This is an open access article distributed under the Creative Commons Attribution License, which permits unrestricted use, distribution, and reproduction in any medium, provided the original work is properly cited.

\begin{abstract}
Forced axisymmetric response of polar orthotropic circular plates of linearly varying thickness resting on Winkler type of elastic foundation has been studied on the basis of classical plate theory. An approximate solution of problem has been obtained by Rayleigh Ritz method, which employs functions based upon the static deflection of polar orthotropic circular plates. The effect of transverse loadings has been studied for orthotropic circular plate resting on elastic foundation. The transverse deflections and bending moments are presented for various values of taper parameter, rigidity ratio, foundation parameter, and flexibility parameter under different types of loadings. A comparison of results with those available in literature shows an excellent agreement.
\end{abstract}

\section{Introduction}

The study of vibrational characteristics of plates has been of great interest due to their increasing use in various engineering applications. The development of fibre-reinforced composite materials and their extensive use in fabrication of plate type structural components in aerospace, ocean engineering, and electronic and mechanical components has led to the study of dynamic response of anisotropic plates. The consideration of thickness variation together with anisotropy not only reduces the size and weight of components but also meets the desirability of high strength, corrosion resistance, high temperature performance, and economy. One can fabricate the orthotropic nature of plate in different ways, that is, rectangular and polar orthotropy. The consideration of polar orthotropy in circular and annular plates provides the best approximation to the results, because polar coordinate axes are also the axes for the materials symmetry. An excellent review of vibration of plates has been given by Leissa in his monograph [1] and a series of review articles [2-7]. Reddy [8] and Lal and Gupta [9] have presented an up-to-date survey analysing transverse vibrations of nonuniform rectangular orthotropic plates. In a recent study, Sayyad and Ghugal [10] presented a review of recent literatures on free vibration analysis of Laminated Composite and Sandwich Plates.
A considerable amount of work dealing with vibration of polar orthotropic circular and annular plates of uniform/nonuniform thickness in presence/absence of elastic foundation has been done by a number of workers and is reported in [11-31] to mention a few. The orthotropic plates resting on an elastic foundation find their application in foundation engineering, such as reinforced concrete pavements of high runways, foundation of deep wells and storage tanks, and slabs of buildings (Lekhnitskii [11], p. 136). In this connection, various models such as Winkler [12-17], Pasternak [18], and Vlasov [19] have been proposed in the literature. Laura et al. [13] studied the effect of Winkler Foundation on vibrations of solid circular plate of linearly varying thickness. Gupta et al. [14] analysed the effect of elastic foundation on axisymmetric vibrations of polar orthotropic circular plates of variable thickness. Further the work has been extended to asymmetric vibration of polar orthotropic plates resting on elastic foundation by Ansari and Gupta [15]. Gupta et al. [16] studied buckling and vibration of polar orthotropic circular plate attached to Winkler Foundation. Orthotropic circular/annular plates such as deck, diaphragm, and bulk heads are used as structural components in launch vehicles.

In some technological situations, a plate is exposed to transverse loads on the surfaces with a downward and/or upward thrust, that is, ship container and aeronautical 
structural components. The stability of these components increases with the support of elastic foundations. Thus the study of the combined effect of transverse loads and elastic foundation on vibrational characteristics of plates is of practical importance. Gupta et al. [16] analysed the complicating effect of elastic foundation on elastic properties of the plates. A number of research papers are available showing the study of transverse deflection and bending moments of polar orthotropic/isotropic plates of variable thickness resting on elastic foundation [20-31] with complicating effects.

The present work is concerned with the study of transverse loads on vibration of polar orthotropic circular plates of linearly varying thickness resting on Winkler type of elastic foundation. The support of elastic foundation provides greater stability to these structural components exposed to transverse loads. An approximate solution is obtained by Ritz method employing functions based on static deflection given by Lekhnitskii [11]. The present choice of functions has a faster rate of convergence as compared to polynomial coordinate functions employed by Laura et al. [13, 21, 26, 27].

\section{Analysis}

Consider a thin circular plate of radius $a$ and variable thickness $h=h(r)$, resting on elastic foundation of modulus $k_{f}$, elastically restrained against rotation by springs of stiffness $k_{\phi}$ and subjected to $P(r) \cos \omega t$ type of excitation extending from $r=r_{0}$ to $r=r_{1}$. Let $(r, \theta)$ be the polar coordinates of any point on the neutral surface of the circular plate referred to as the centre of the plate as origin (shown in Figure 1(a)).

The maximum kinetic energy of the plate is given by

$$
T_{\max }=\frac{1}{2} \rho \omega^{2} \int_{0}^{a} \int_{0}^{2 \pi} h w^{2} r d \theta d r
$$

where $w$ is the transverse deflection, $\rho$ the mass density, and $\omega$ the frequency in radians per second.

The maximum strain energy of the plate is given by

$$
\begin{aligned}
& U_{\max }=\frac{1}{2} \int_{0}^{a} \int_{0}^{2 \pi}\left[D_{r}\left\{\left(\frac{\partial^{2} w}{\partial r^{2}}\right)^{2}+2 v_{\theta} \frac{\partial^{2} w}{\partial r^{2}}\left(\frac{1}{r} \frac{\partial w}{\partial r}\right)\right\}\right. \\
& \left.+D_{\theta}\left(\frac{1}{r} \frac{\partial w}{\partial r}\right)^{2}+k_{f} w^{2}\right] r d r d \theta+\frac{1}{2} \\
& \cdot a k_{\phi} \int_{0}^{2 \pi}\left(\frac{\partial w(a, \theta)}{\partial r}\right)^{2} d \theta,
\end{aligned}
$$

where $1 / k_{\phi}$ is the rotational flexibility of the spring and flexural rigidities of the plate are

$$
\begin{aligned}
& D_{r}=\frac{E_{r} h^{3}}{12\left(1-v_{r} v_{\theta}\right)}, \\
& D_{\theta}=\frac{E_{\theta} h^{3}}{12\left(1-v_{r} v_{\theta}\right)} .
\end{aligned}
$$

The work done by the external force $P(r)$ acting on the plate in the direction parallel to $z$-axis is given by

$$
V_{\max }=\int_{0}^{2 \pi} d \theta \int_{r_{0}}^{r_{1}} w P(r) r d r
$$

\section{Method of Solution: Ritz Method}

Ritz method requires that the functional

$$
\begin{aligned}
& J(w)=U_{\max }-V_{\max }-T_{\max }=\frac{1}{2} \\
& \cdot \int_{0}^{a} \int_{0}^{2 \pi}\left[D_{r}\left\{\left(\frac{\partial^{2} w}{\partial r^{2}}\right)^{2}+2 v_{\theta} \frac{\partial^{2} w}{\partial r^{2}}\left(\frac{1}{r} \frac{\partial w}{\partial r}\right)\right\}\right. \\
& \left.+D_{\theta}\left(\frac{1}{r} \frac{\partial w}{\partial r}\right)^{2}+k_{f} w^{2}\right] r d r d \theta+\frac{1}{2} \\
& \cdot a k_{\phi} \int_{0}^{2 \pi}\left(\frac{\partial w(a, \theta)}{\partial r}\right)^{2} d \theta-\int_{0}^{2 \pi} d \theta \int_{r_{0}}^{r_{1}} w P(r) \\
& \cdot r d r-\frac{1}{2} \rho \omega^{2} \int_{0}^{a} \int_{0}^{2 \pi} h w^{2} r d \theta d r
\end{aligned}
$$

be minimised.

Uniformly distributed load $P_{0}$ extending from $r_{0}$ to $r_{1}$ is given by

$$
P(r)=q_{0}=\frac{P_{0}}{\pi\left(r_{1}^{2}-r_{0}^{2}\right)}\left[U\left(r-r_{0}\right)-U\left(r-r_{1}\right)\right] .
$$

Introducing the nondimensional variables $R=r / a, R_{1}=$ $r_{1} / a, R_{0}=r_{0} / a$ and assuming the deflection function as $W(R)=w /\left(a^{4} q_{0} D_{r_{0}}\right)$

$$
W(R)=\sum_{i=0}^{m} A_{i} F_{i}(R)=\sum_{i=0}^{m} A_{i}\left(1+\alpha_{i} R^{4}+\beta_{i} R^{1+p}\right) R^{2 i},
$$

where $A_{i}$ are undetermined coefficients, $p^{2}=E_{\theta} / E_{r}$, and $\alpha_{i}$, $\beta_{i}$ are unknown constants to be determined from boundary conditions (Leissa [1], p. 14):

$$
\begin{aligned}
K_{\phi} \frac{d F_{i}(1)}{d R} & =-(1-\alpha)^{3}\left[\frac{d^{2} F_{i}}{d R^{2}}+v_{\theta}\left(\frac{1}{R} \frac{d F_{i}}{d R}\right)\right]_{R=1} \\
F_{i}(1) & =0 .
\end{aligned}
$$

Linearly thickness variation of the plate is assumed as $h=$ $h_{0}(1-\alpha R)$, where $\alpha$ and $h_{0}$ are taper parameter and thickness of the plate at the centre, respectively.

The choice of the function approximating the deflection of the plate $W(R)$ given in (7) is based upon the static deflection polar orthotropic plates (Lekhnitskii [11]), which has faster rate of convergence (Gupta et al. [16]) as compared to the polynomial coordinate functions used by earlier researchers $[13,21,26,27]$. 


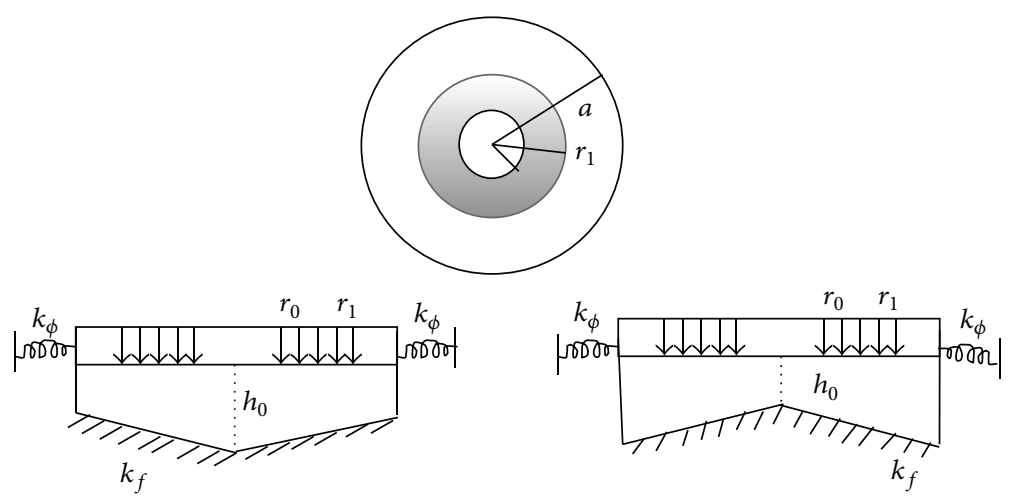

(a)

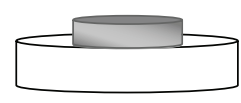

Disk loaded plate

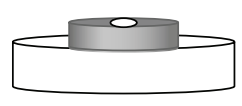

Annular loaded plate

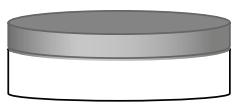

Uniformly loaded plate

(b)

FIGURE 1: (a) Plate geometry with side and surface views. (b) Loading structure of the plate.

Introducing the nondimensional variables $W$ and $R$ in (5), the functional $J(W)$ becomes

$$
\begin{aligned}
& J(W)=\pi D_{r_{0}}\left[\int _ { 0 } ^ { 1 } ( 1 - \alpha R ) ^ { 3 } \left\{\left(\frac{\partial^{2} W}{\partial R^{2}}\right)^{2}\right.\right. \\
& \left.+2 v_{\theta} \frac{\partial^{2} W}{\partial R^{2}}\left(\frac{1}{R} \frac{\partial W}{\partial R}\right)+p^{2}\left(\frac{1}{R} \frac{\partial W}{\partial R}\right)^{2}+K_{f} W^{2}\right\} \\
& \cdot R d R+K_{\phi} \int_{0}^{2 \pi}\left(\frac{\partial W(1)}{\partial R}\right)^{2} d \theta-\int_{R_{0}}^{R_{1}} 2 W(R) R d R \\
& \left.-\Omega^{2} \int_{0}^{1} \int_{0}^{2 \pi}(1-\alpha R) W^{2} R d R\right],
\end{aligned}
$$

where

$$
\begin{aligned}
D_{r_{0}} & =\frac{E_{r} h_{0}{ }^{3}}{12\left(1-v_{r} v_{\theta}\right)}, \\
\Omega^{2} & =\frac{a^{4} \omega^{2} \rho h_{0}}{D_{r_{0}}}, \\
K_{f} & =\frac{a^{4} k_{f}}{D_{r_{0}}}, \\
K_{\Phi} & =\frac{a k_{\Phi}}{D_{r_{0}}} .
\end{aligned}
$$

The minimisation of the functional $J(W)$ given by (9) requires

$$
\frac{\partial J(W)}{\partial A_{i}}=0, \quad i=0,1,2,3, \ldots, m .
$$

This leads to a system of nonhomogeneous equations in $A_{j}$,

$$
\left(a_{i j}-b_{i j}\right) A_{j}=C_{i}, \quad i, j=0,1, \ldots, m,
$$

where $A=\left[a_{i j}\right]$ and $B=\left[b_{i j}\right]$ are square matrices of order $m+1$ given by

$$
\begin{aligned}
a_{i j} & =\int_{0}^{1}(1-\alpha R)^{3}\left[F_{i}^{\prime \prime} F_{j}^{\prime \prime}+2 v_{\theta} F_{i}^{\prime \prime}\left(\frac{F_{j}^{\prime}}{R}\right)\right. \\
& \left.+p^{2}\left(\frac{F_{i}^{\prime}}{R}\right)\left(\frac{F_{j}^{\prime}}{R}\right)+K_{f} F_{i} F_{j}\right] R d R+K_{\phi} F_{i}^{\prime}(1) \\
& \cdot F_{j}^{\prime}(1), \\
b_{i j} & =\int_{0}^{1}(1-\alpha R) F_{i} F_{j} R d R, \\
C_{i j} & =\int_{0}^{1} 2 F_{i} R d R .
\end{aligned}
$$

The solution of system of (12) gives the value of $A_{i}$ and thus the transverse deflection $W$ and the radial and transverse bending moments

$$
\begin{aligned}
& \frac{M_{r}}{a^{2} q_{0}}=-(1-\alpha R)^{3}\left[\frac{d^{2} W}{d R^{2}}+v_{\theta} \frac{1}{R} \frac{d W}{d R}\right], \\
& \frac{M_{\theta}}{a^{2} q_{0}}=-(1-\alpha R)^{3}\left[v_{\theta} \frac{d^{2} W}{d R^{2}}+p^{2} \frac{1}{R} \frac{d W}{d R}\right]
\end{aligned}
$$

are computed.

\section{Numerical Results}

Numerical results have been calculated for different values of taper parameter $\alpha(= \pm 0.3), E_{\theta} / E_{r}(=5.0)$, and foundation 


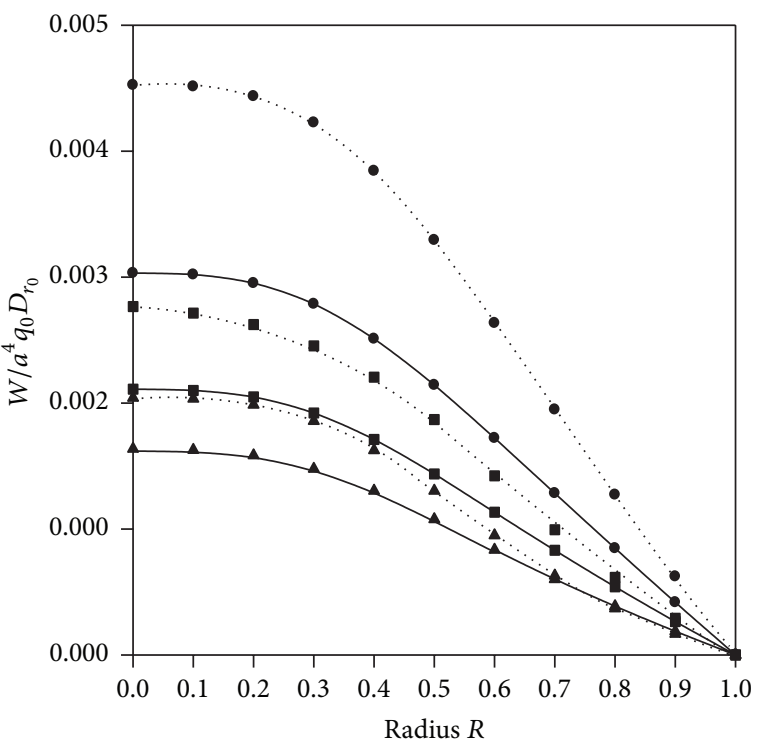

(a) Disk loading (SS-plate)

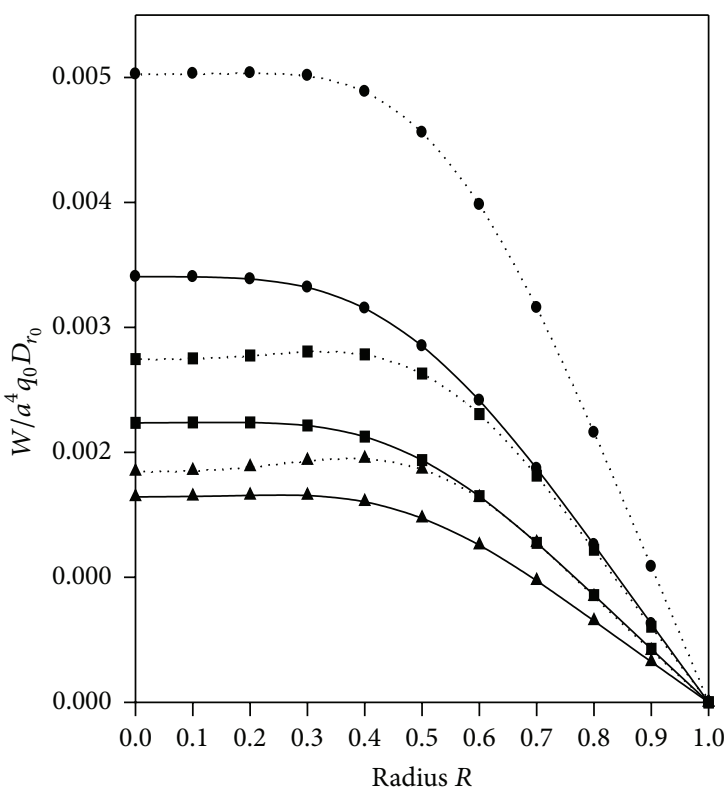

(c) Annular loading (SS-plate)

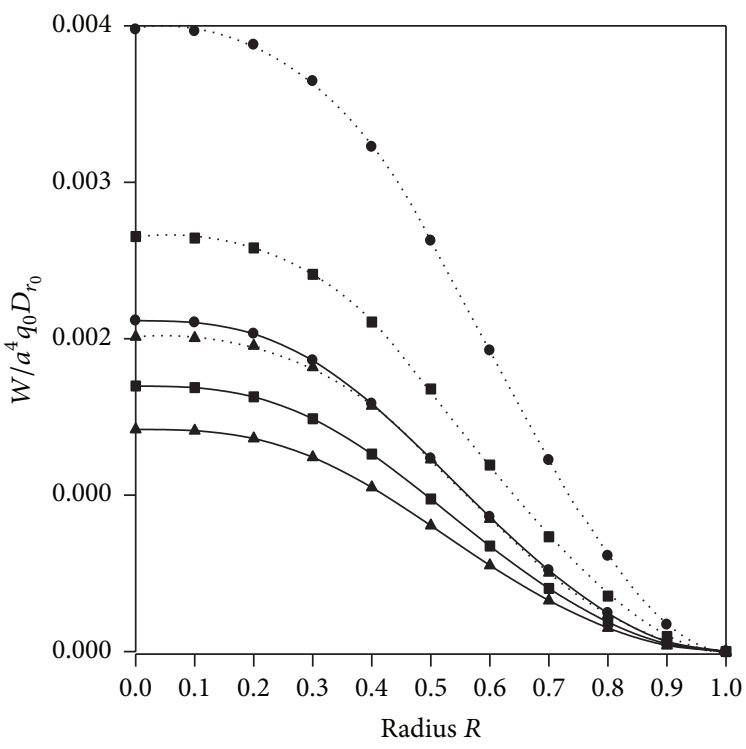

(b) Disk loading (CL-plate)

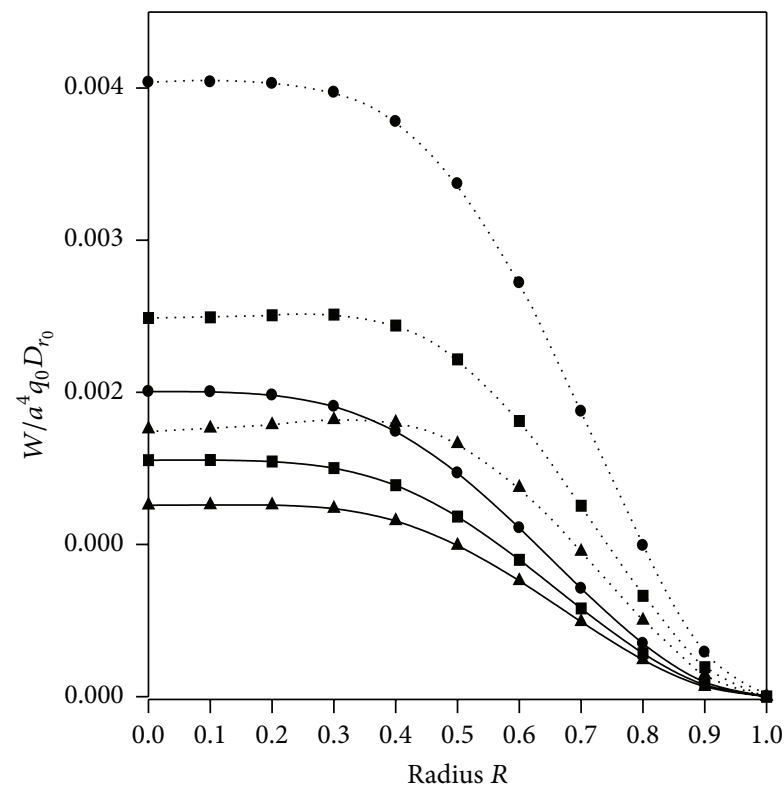

(d) Annular loading (CL-plate)

Figure 2: Radius vector versus deflection parameter $W / a^{4} q_{0} D_{r_{0}}$ for taper parameter $\alpha=-0.3:-$ and $\alpha=0.3: \ldots$ Keys foundation parameter $K_{f}=0.01: \bullet \bullet, K_{f}=0.02: \mathbf{m}$, and $K_{f}=0.03: \mathbf{\Delta \Lambda .}$.

modulus $K_{f}(=0.01,0.02,0.03)$ for forced vibration of polar orthotropic circular plate with simply supported (SS-plate) and clamped (CL-plate) edges. The plate is subjected under different types of loadings such as uniform loading on entire plate, annular loading, and disk loading. The natural frequencies for free vibration are obtained by putting $P(r)=$ 0 . In case of forced vibration the nondimensional frequency parameter is taken as $\Omega=\eta \Omega_{00}$ for $\Omega<\Omega_{00}$ and $\Omega=$ $\Omega_{00}+\eta\left(\Omega_{01}-\Omega_{00}\right)$ for $\Omega_{00}<\Omega<\Omega_{01}$, where $\eta=0.2$. The normalised deflection and bending moments are obtained for fixed value of Poisson's ratio as 0.3 .

\section{Discussion}

Forced axisymmetric response of polar orthotropic circular plates of linearly varying thickness has been analysed for various values of plate parameters. Transverse deflection and bending moments are obtained for circumferentially stiffened plate, that is, $E_{\theta}>E_{r}$. Bending moments of the plate cannot be obtained for radially stiffened plate $E_{\theta}>E_{r}$, because infinite stress is developed at the centre in this case (Lekhnitskii [11], p. 372). Transverse deflection and bending moments are presented here under different types of loadings: 


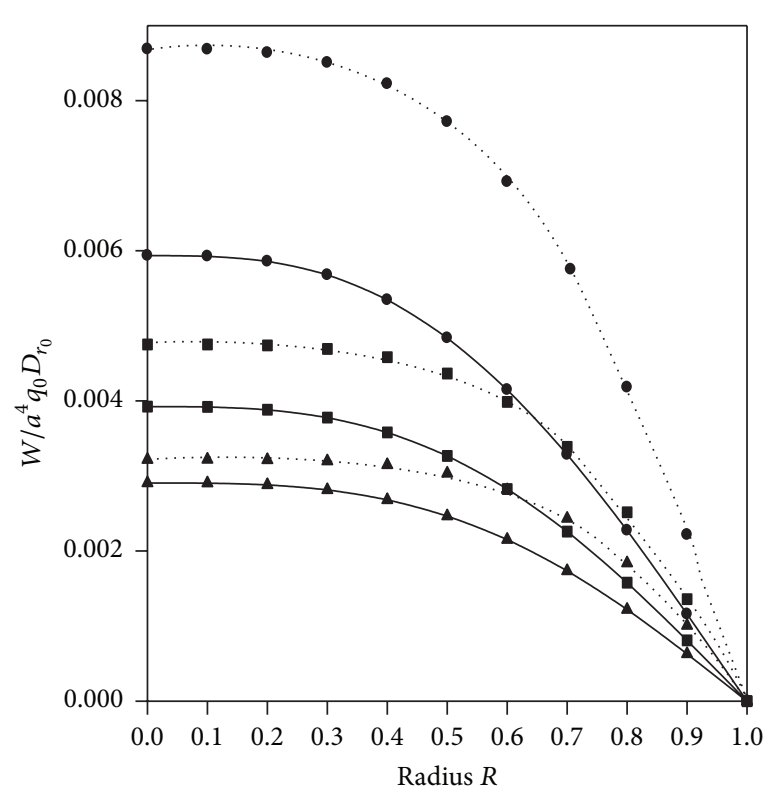

(a) Uniform loading (SS-plate)

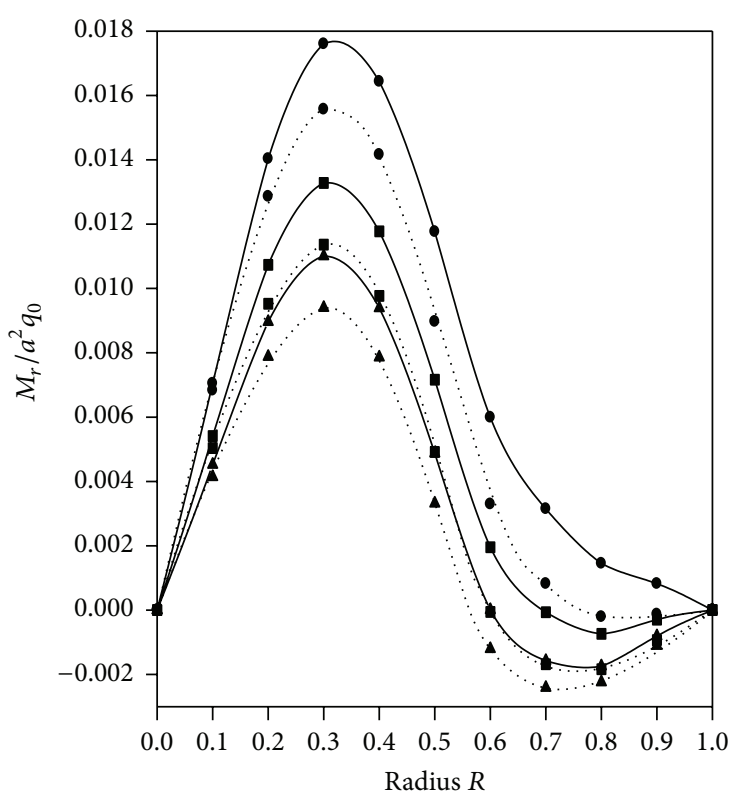

(c) Disk loading (SS-plate)

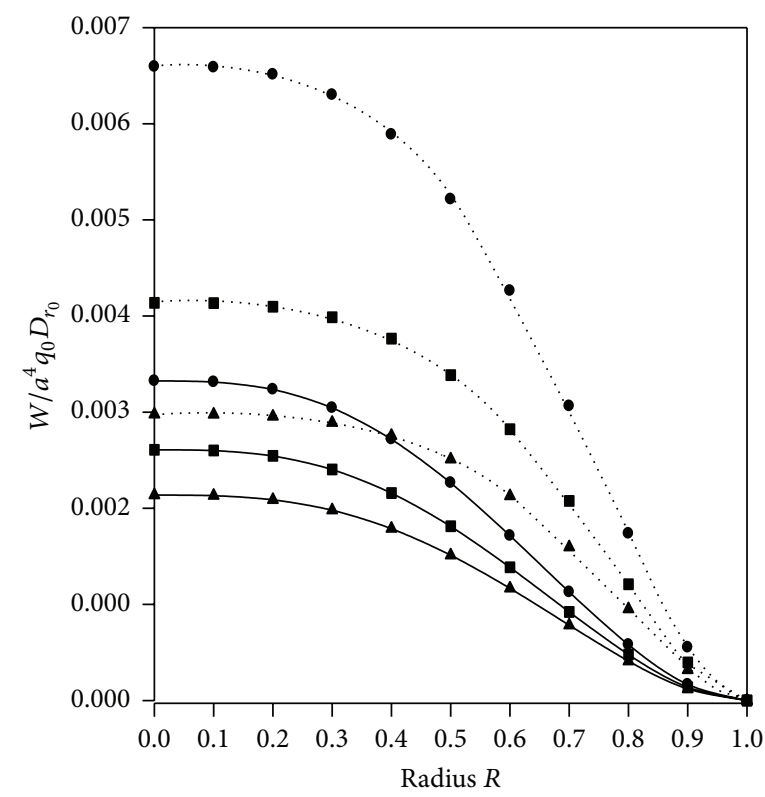

(b) Uniform loading (CL-plate)

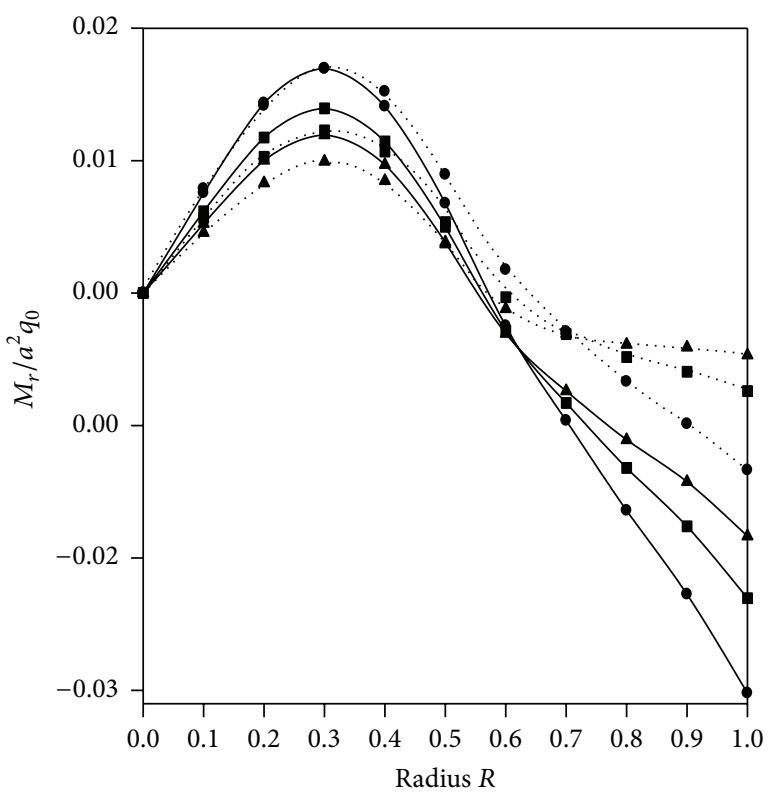

(d) Disk loading (CL-plate)

FIGURE 3: Radius vector versus radial bending moment $M_{r} / a^{2} q_{0}$ for taper parameter $\alpha=-0.3:-$ and $\alpha=0.3: \ldots$ Keys foundation parameter $K_{f}=0.01: \bullet \bullet, K_{f}=0.02: \mathbf{m}$, and $K_{f}=0.03: \mathbf{\Delta \Lambda .}$.

(a) When load is distributed uniformly on the disk extending from $R_{0}=0.0$ to $R_{1}=0.5$ (disk loaded plate).

(b) When load is distributed uniformly on the annular region extending from $R_{0}=0.3$ to $R_{1}=0.7$ (annular loaded plate).

(c) When load is distributed uniformly on the entire region extending from $R_{0}=0.0$ to $R_{1}=1.0$ (uniformly loaded plate).

The total load on the plate is the same in all three cases (shown in Figure 1(b)).
The whole analysis of numerical results is presented in Figures 2, 3, 4, 5, 6(a), and 6(b) for $\Omega<\Omega_{00}$ and $E_{\theta} / E_{r}=5.0$ for different values of plate parameters of simply supported (SS) and clamped (CL) edges. The transverse deflection for all three cases of loading for SS- and CL-plate is presented in Figures 2, 3(a), and 3(b). Figure 2(a) presents the transverse deflection of polar orthotropic simply supported plates along the radius vector $R$ for taper parameter $\alpha= \pm 0.3$ and foundation parameter $K_{f}=0.01,0.02$, and 0.03 under disk loading. The transverse deflection is maximum at the centre of the plate, which decreases as the foundation parameter $K_{f}$ increases, keeping other plate parameters fixed. Thus the 


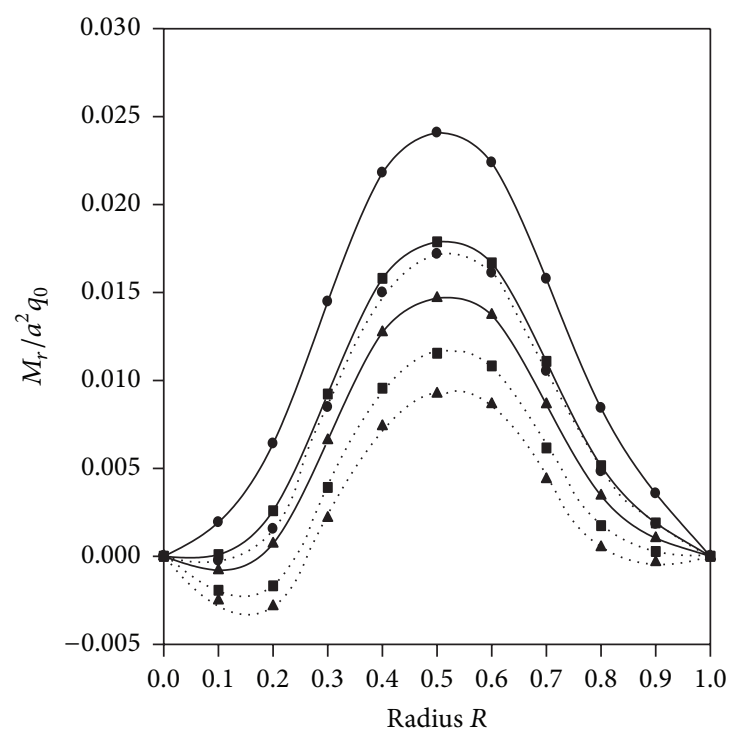

(a) Annular loading (SS-plate)

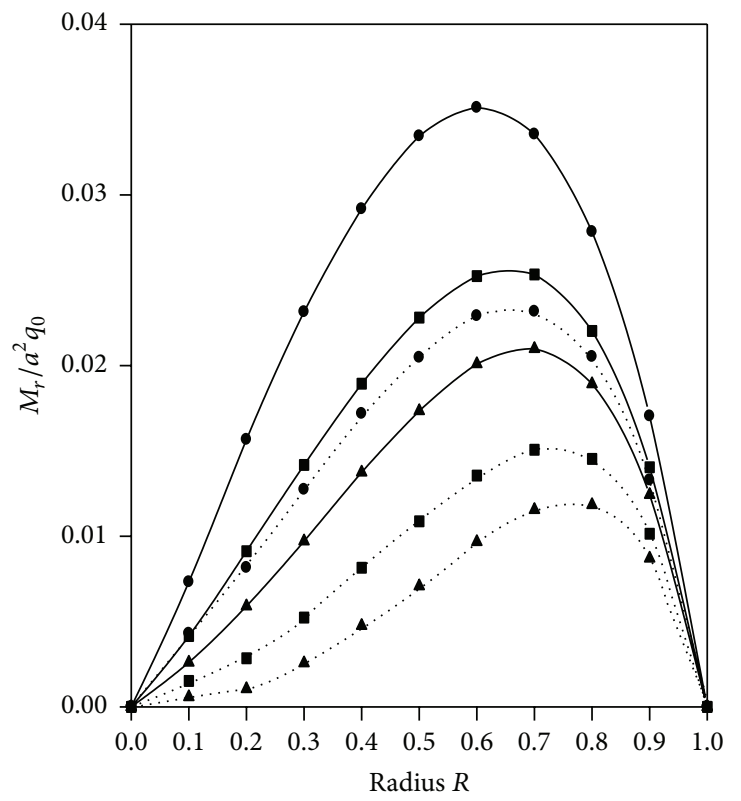

(c) Uniform loading (SS-plate)

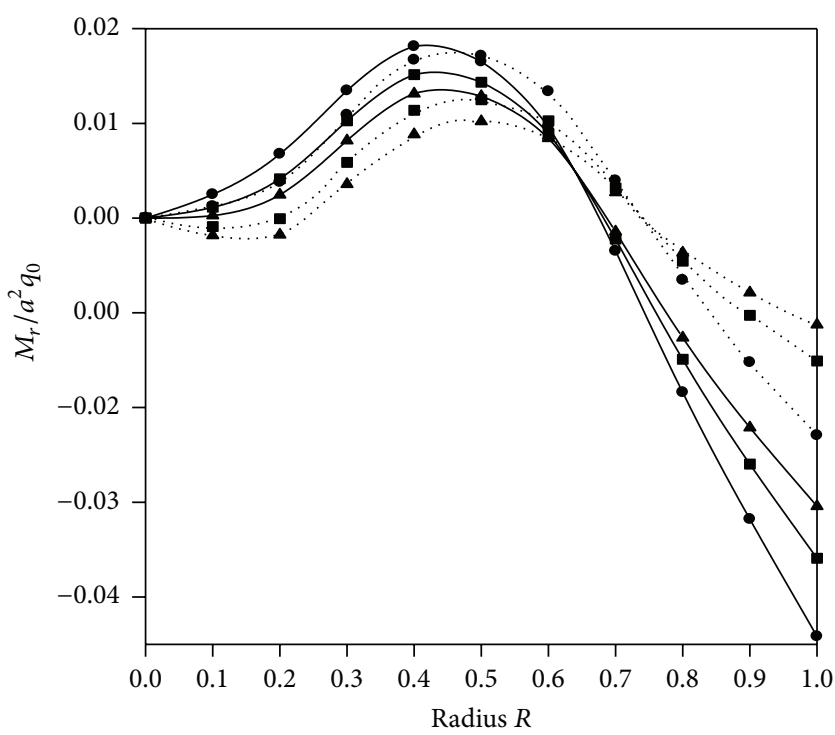

(b) Annular loading (CL-plate)

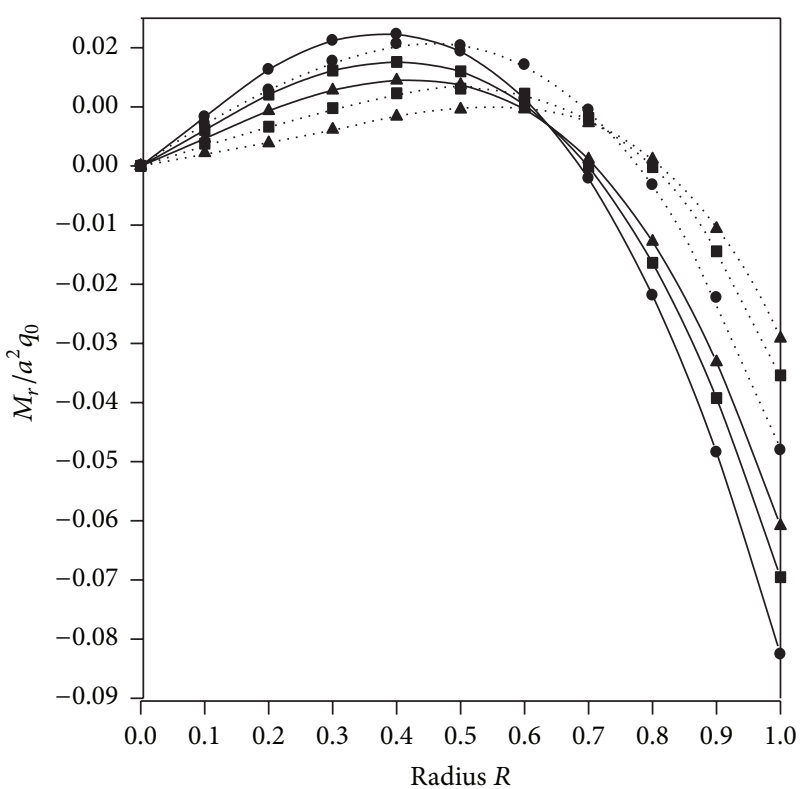

(d) Uniform loading (CL-plate)

FIGURE 4: Radius vector versus radial bending moment $M_{r} / a^{2} q_{0}$ for taper parameter $\alpha=-0.3:-$ and $\alpha=0.3: \ldots$. Keys foundation parameter $K_{f}=0.01: \bullet \bullet, K_{f}=0.02: \cdots$, and $K_{f}=0.03: \mathbf{\Delta \Lambda}$.

elastic stability of the plate under loading is more, if some elastic foundation to the structural component is provided. Figure also shows that the transverse deflection for taper parameter $\alpha=0.3$ (centrally thicker plate) is greater than that for $\alpha=-0.3$ (centrally thinner plate), the reason being greater mass attribution at the centre in case of centrally thicker plate. The centrally thicker plate having higher amplitude of deflection can be protected from being damaged using foundation. This type of structural components is highly used in civil, mechanical, aeronautical, and modern technology. The idea of structural stability in these fields is very essential for design engineer to know before. Figure 2(b) presents that transverse deflection for clamped plate under disk loading for the same plate parameters as in Figure 2(a). It has been observed that the transverse deflection gradually decreases as the flexibility parameter $K_{\phi}$ increases for elastically restrained plate. Thus the transverse deflection for clamped plate is always less than that for simply supported plate, keeping other plate parameters fixed. The effect of foundation parameter $K_{f}$ on transverse deflection for clamped plate shows that deflection at the centre decreases more rapidly for centrally thicker plate than that for centrally thinner plate, the reason being more mass attribution for centrally thicker plate. Though values are nearly close, the foundation parameter $K_{f}$ increases nature of variation of transverse deflection of CL-plate which is found to be different. Figures 2(c) and 


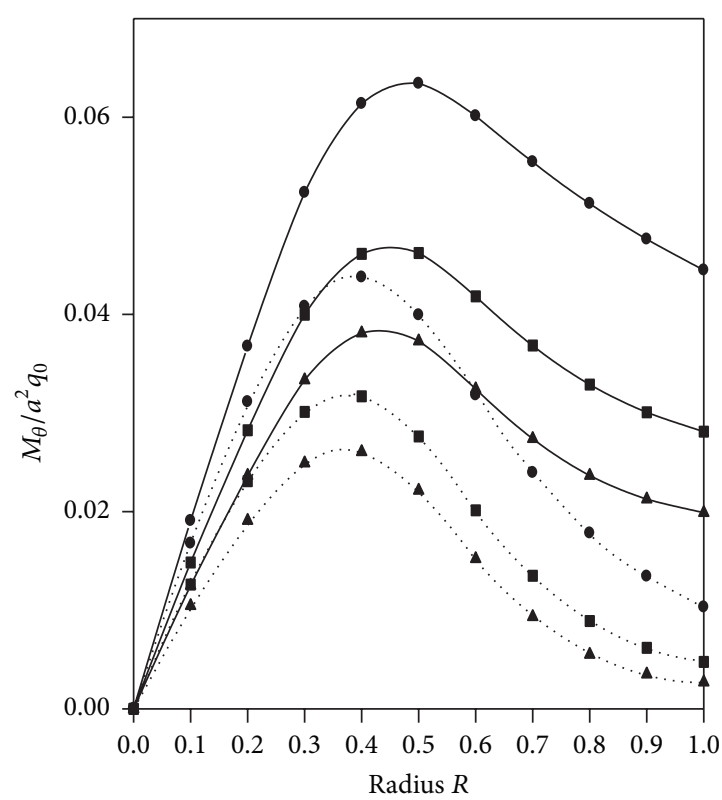

(a) Disk loading (SS-plate)

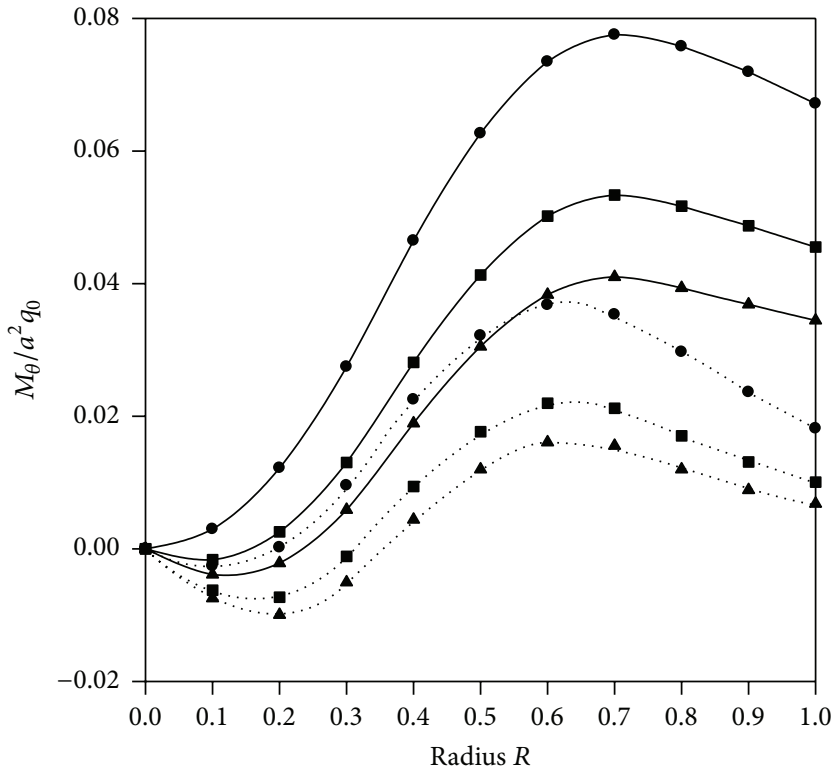

(c) Annular loading (SS-plate)

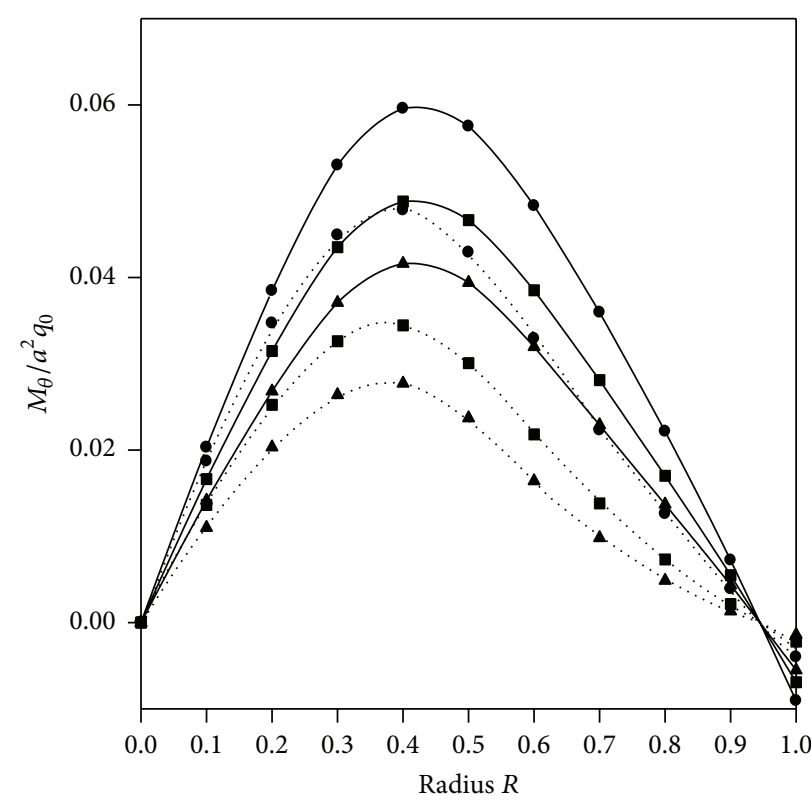

(b) Disk loading (CL-plate)

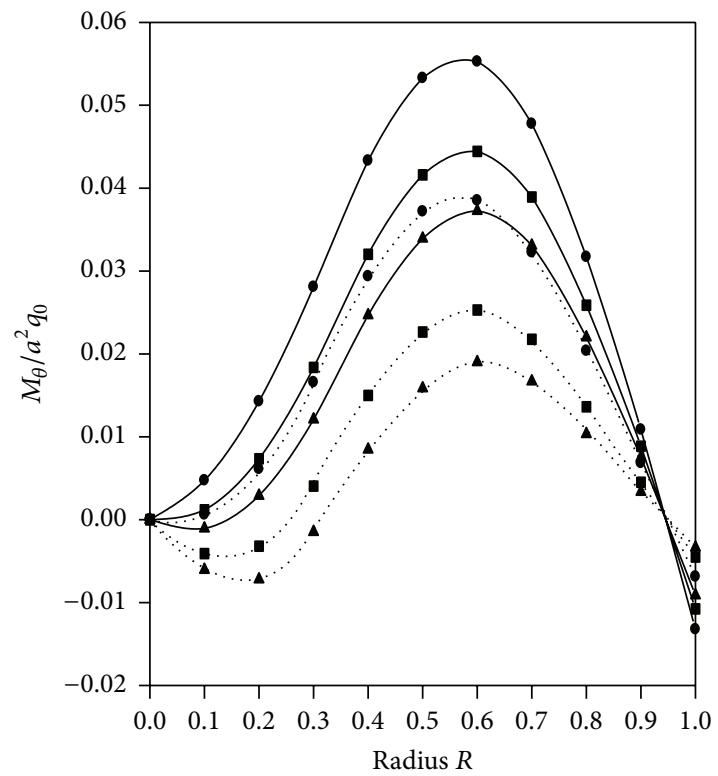

(d) Annular loading (CL-plate)

FIGURE 5: Radius vector versus tangential bending moment $M_{\theta} / a^{2} q_{0}$ for taper parameter $\alpha=-0.3:-$ and $\alpha=0.3: \ldots$ Keys foundation parameter $K_{f}=0.01: \cdots, K_{f}=0.02: \cdots$, , and $K_{f}=0.03: \mathbf{\Delta \Lambda}$.

2(d) present the transverse deflection when load is annular extending from $R_{0}=0.3$ to $R_{1}=0.7$ for SS- and CL-plates, respectively. Transverse deflection for annular loaded plate is found to be greater than that for disk loaded plate; of course it depends on the position of annular region of loading. The effect on deflection for simply supported plate is more than that of clamped plate. Transverse deflection for uniformly loaded plate is observed to be maximum as compared to disk and annular loaded plates as shown in Figures 3(a) and 3(b).

The radial bending moments for disk, annular, and uniformly loaded SS- and CL-plates are presented in Figures 3(c), 3(d), 4(a), 4(b), 4(c), and 4(d). Radial bending moment for disk loaded plate is presented in Figures 3(c) and 3(d). Figures show that radial bending moment for $\alpha=-0.3$ is greater than that for $\alpha=0.3$, other plate parameters being fixed. It is observed that peak of the bending moment decreases as the foundation parameter $K_{f}$ increases. Maximum radial bending moment occurs at $R=0.35$ for disk loaded plate for these plate parameter values, whereas in case of annular loaded plate peak of the bending moment occurs at $R=0.5$. Peak of the bending moment shifts towards the edge $R=1.0$ for uniformly loaded plate (shown in Figures 4(a) and 4(b)). Radial bending moment at the edge increases as the flexibility parameter $K_{\phi}$ increases and is maximum for C1 plate. Radial 


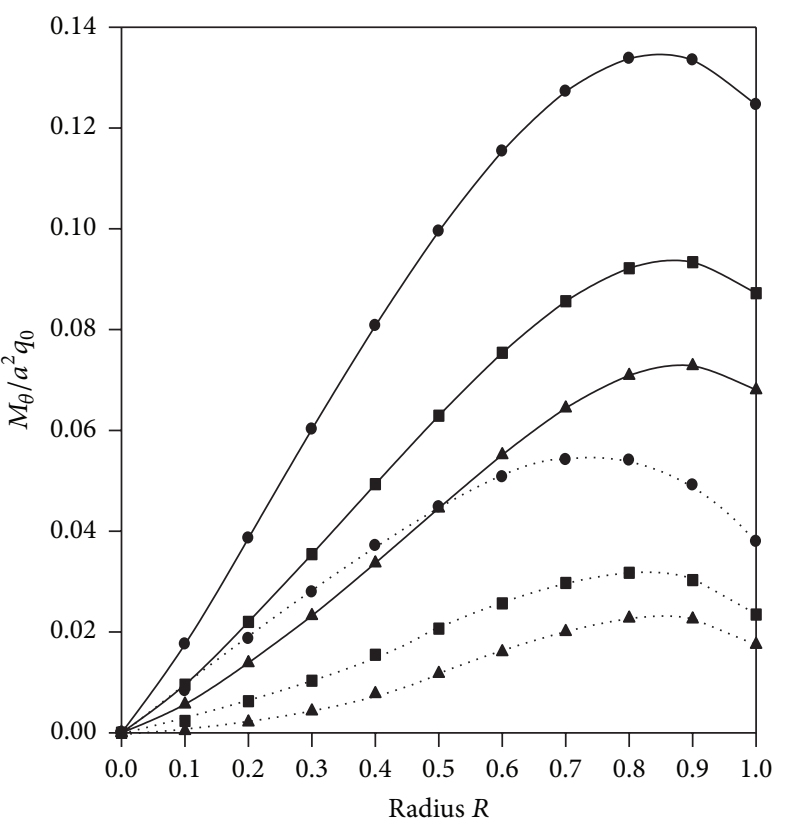

(a) Uniform loading (SS-plate)

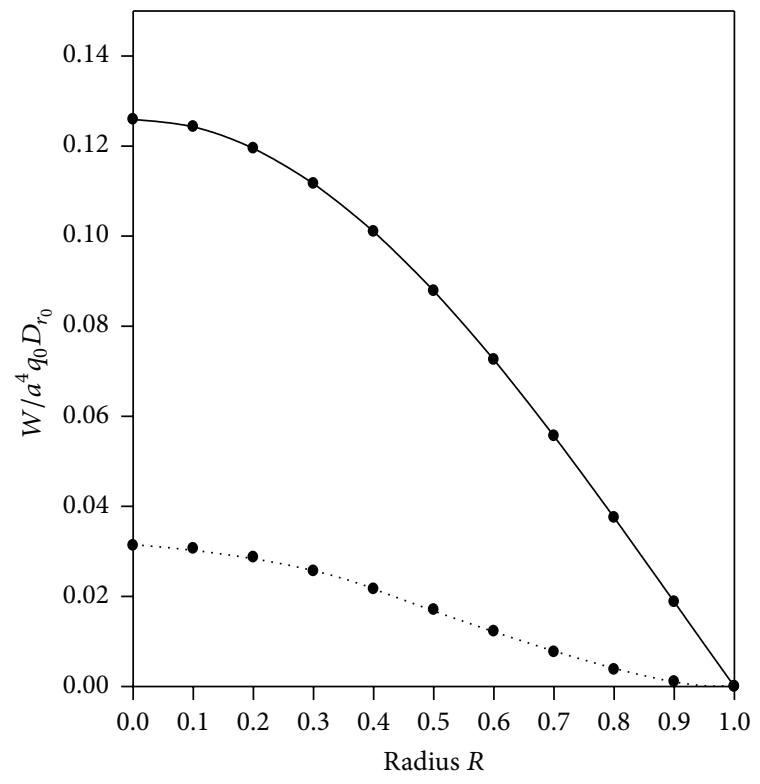

(c) Radius vector versus transverse deflection

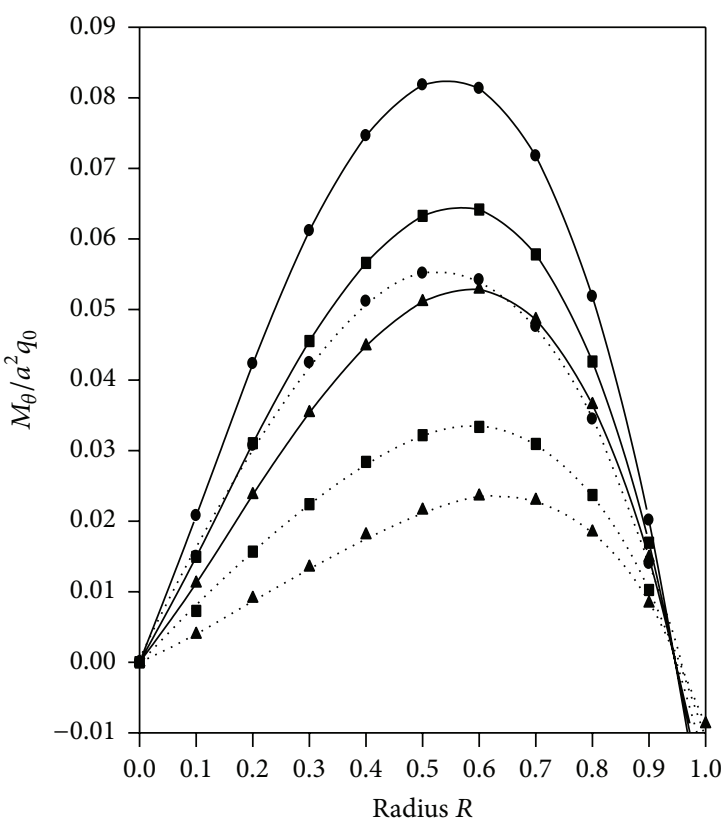

(b) Uniform loading (CL-plate)

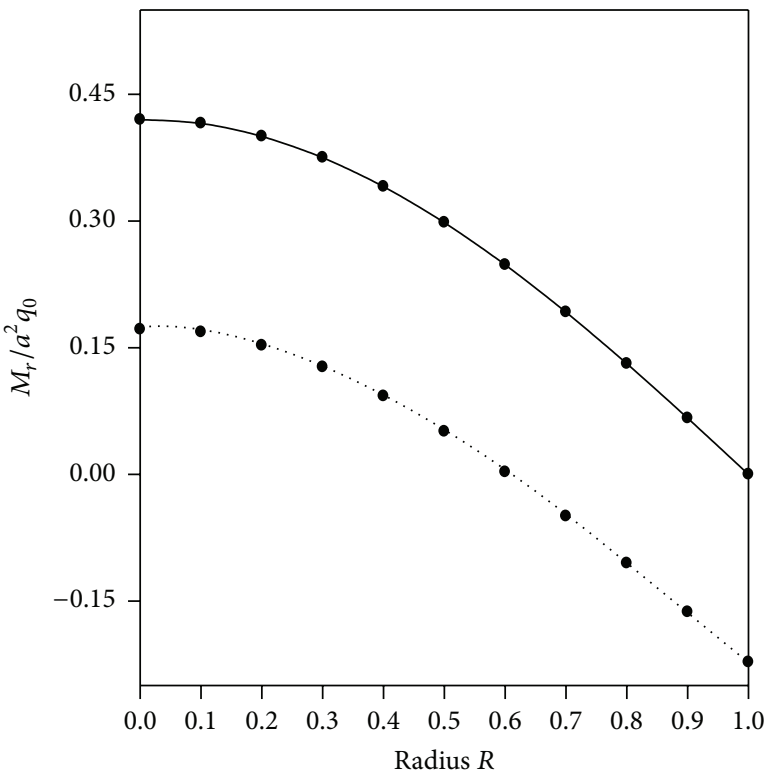

(d) Radius vector versus bending moment

FIGURE 6: (•) values in Figures 6(c) and 6(d) are taken from [26] for SS-plate: - and CL-plate: ..., respectively.

bending moment for $\alpha=-0.3$ is greater than that for $\alpha=0.3$, which decreases as the foundation parameter $K_{f}$ increases. Maximum bending moment at the edge occurs when the plate is uniformly loaded (Figures $4(\mathrm{c})$ and $4(\mathrm{~d})$ ) compared to those of disk and annular loaded plates. Tangential bending moments are also presented in Figures 5(a), 5(b), 5(c), 5(d), 6(a), and 6(b) under three types of loadings. Radial bending moment at the edge for SS orthotropic plate is zero, but the tangential bending moment is nonzero. Tangential bending moment at the edge for SS-plate is greater than that of $\mathrm{Cl}$ plate for corresponding value of plate parameters. The present choice of function considered in the study has faster rate of convergence as compared to the polynomial coordinate function used by earlier researchers [13, 21, 26, 27] (see Figure 7).

Table 1 compares the deflection and radial bending moment at the centre of the plate for $\Omega<\Omega_{00}$ and $\Omega_{00}<$ $\Omega<\Omega_{01}$ for uniform isotropic plate obtained by Laura et al. [24] using Ritz method. Table 2 compares the transverse deflection of simply supported plate of variable thickness. Figure 6(c) compares the transverse deflection with the result of Laura et al. [26] for uniformly loaded isotropic circular plate of constant thickness with simply supported and clamped edge, respectively, obtained by Glarkin's method. 


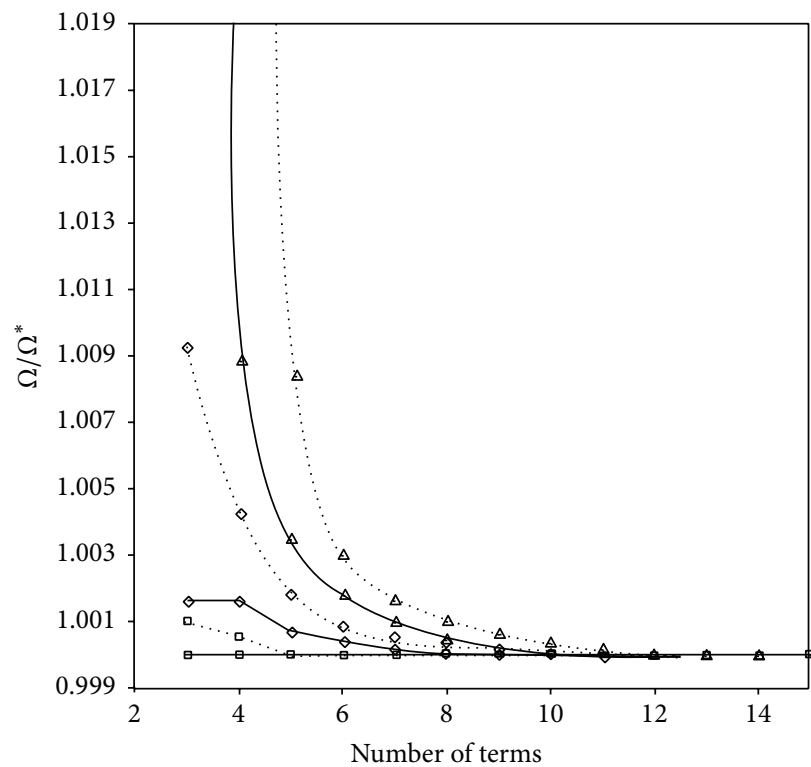

Figure 7: Normalised frequency parameter $\Omega / \Omega^{*}$ for first three natural frequencies in fundamental mode: $\square \square \square$, second Mode: $\diamond \diamond \diamond$, and third mode: $\triangle \triangle \triangle$ for CL-plate with $E_{\theta} / E_{r}=5.0, n=1, \alpha=0.3$. Keys present method: - and polynomial coordinate method: ..., where $\Omega^{*}$ is the frequency obtained using 15 terms.

TABLE 1: Comparison of displacement and radial bending moment at the centre as a function of $\eta\left(=\Omega<\Omega_{00}\right)$ and $\left(=\Omega_{00}<\Omega<\Omega_{01}\right)$ for uniform isotropic circular plate.

\begin{tabular}{|c|c|c|c|c|c|c|c|c|c|}
\hline & \multirow{3}{*}{$\eta$} & \multicolumn{4}{|c|}{$\Omega<\Omega_{00}$} & \multicolumn{4}{|c|}{$\Omega_{00}<\Omega<\Omega_{01}$} \\
\hline & & \multicolumn{2}{|c|}{$W / a^{4} q_{0} D_{r_{0}}$} & \multicolumn{2}{|c|}{$M_{r} / a^{2} q_{0}$} & \multicolumn{2}{|c|}{$W / a^{4} q_{0} D_{r_{0}}$} & \multicolumn{2}{|c|}{$M_{r} / a^{2} q_{0}$} \\
\hline & & Reference [24] & Present & Reference [24] & Present & Reference [24] & Present & Reference [24] & Present \\
\hline \multirow{4}{*}{$\begin{array}{l}\text { CL-plate } \\
\Omega_{00}=10.2158 \\
\Omega_{01}=39.771\end{array}$} & 0.2 & 0.0160 & 0.01630 & 0.085 & 0.08524 & 0.0110 & 0.01181 & 0.084 & 0.08468 \\
\hline & 0.4 & 0.01872 & 0.01873 & 0.099 & 0.09952 & 0.0055 & 0.00553 & 0.051 & 0.05121 \\
\hline & 0.6 & 0.02479 & 0.02471 & 0.135 & 0.13533 & 0.0040 & 0.00404 & 0.039 & 0.03840 \\
\hline & 0.8 & 0.0446 & 0.04461 & 0.253 & 0.25281 & 0.0044 & 0.00446 & 0.080 & 0.08001 \\
\hline \multirow{4}{*}{$\begin{array}{l}\text { SS-plate } \\
\Omega_{00}=4.9351 \\
\Omega_{01}=29.721\end{array}$} & 0.2 & 0.0664 & 0.06640 & 0.215 & 0.21554 & 0.0226 & 0.02263 & 0.094 & 0.09407 \\
\hline & 0.4 & 0.0760 & 0.07603 & 0.248 & 0.24874 & 0.0094 & 0.00946 & 0.052 & 0.05224 \\
\hline & 0.6 & 0.1001 & 0.10010 & 0.331 & 0.33179 & 0.0062 & 0.006238 & 0.049 & 0.04948 \\
\hline & 0.8 & 0.1787 & 0.17877 & 0.603 & 0.60332 & 0.0063 & 0.006329 & 0.076 & 0.07653 \\
\hline
\end{tabular}

TABLE 2: Comparison of displacements for simply supported circular plate of linearly varying thickness for $v_{\theta}=0.25$.

\begin{tabular}{lcc}
\hline Taper parameter $\alpha$ & Reference [26] & Present \\
\hline-0.5708 & 0.1817 & 0.1815 \\
-0.0 & 0.06568 & 0.0656 \\
-0.33333 & 0.1143 & 0.1127 \\
\hline
\end{tabular}

The bending moments for same plate parameter values as taken by Laura et al. [26] have been also compared and presented in Figure 6(d). Comparison of these obtained results shows an excellent agreement with the result available in the literature.

\section{Conclusion}

The forced vibrational characteristics of polar orthotropic circular plates resting on Winkler type of elastic foundation have been studied using Ritz method. The function based on static deflection of polar orthotropic plates has been used to approximate the transverse deflection of the plate. The present choice of function has faster rate of convergence as compared to the polynomial coordinate function used by earlier researchers. Study shows that the deflection attains maximum value at the centre of the plate under uniform loading. The effect is influenced by thickness variation. Centrally thicker plate has more deflection than that of centrally thinner plate, the region being the more mass attribution at the centre in case of centrally thicker plate. While designing 
a structural component, stability is one of the important factors to be considered. The result analysis shows that the consideration of elastic foundation can protect the system from fatigue failure under heavy loads.

\section{Competing Interests}

The author declares that they have no competing interests.

\section{References}

[1] A. W. Leissa, "Vibration of plates," Tech. Rep. sp-160, NASA, 1969.

[2] A. W. Leissa, "Recent research in plate vibrations: classical theory," The Shock and Vibration Digest, vol. 9, no. 10, pp. 1324, 1977.

[3] A. W. Leissa, "Recent research in plate vibrations 1973-1976: complicating effects," The Shock and Vibration Digest, vol. 10, no. 12, pp. 21-35, 1978.

[4] A. W. Leissa, "Literature review: plate vibration research, 19761980: classical theory," The Shock and Vibration Digest, vol. 13, no. 9, pp. 11-22, 1981.

[5] A. W. Leissa, "Plate vibrations research 1976-1980: complicating effects," The Shock and Vibration Digest, vol. 13, no. 10, pp. 19-36, 1981.

[6] A. W. Leissa, "Recent studies in plate vibrations 1981-1985, part I: classical theory," The Shock and Vibration Digest, vol. 19, no. 2, pp. 11-18, 1987.

[7] A. W. Leissa, "Recent studies in plate vibrations 1981-1985, part II: complicating effects," The Shock and Vibration Digest, vol. 19, no. 3, pp. 10-24, 1987.

[8] J. N. Reddy, Mechanics of Laminated Composite Plates: Theory and Analysis, CRP Press, Boca Raton, Fla, USA, 1997.

[9] R. Lal and U. S. Gupta, "Chebyshev polynomials in the study of transverse vibrations of non-uniform rectangular orthotropic plates," The Shock and Vibration Digest, vol. 33, no. 2, pp. 103-112, 2001.

[10] A. S. Sayyad and Y. M. Ghugal, "On the free vibration analysis of laminated composite and sandwich plates: a review of recent literature with some numerical results," Composite Structures, vol. 129, pp. 177-201, 2015.

[11] S. G. Lekhnitskii, Anisotropic Plates, Breach Science, New York, NY, USA, 1985.

[12] S. Chonan, "Random vibration of an initially stressed thick plate on an elastic foundation," Journal of Sound and Vibration, vol. 71, no. 1, pp. 117-127, 1980.

[13] P. A. A. Laura, R. H. Gutierrez, R. Carnicer, and H. C. Sanzi, "Free vibrations of a solid circular plate of linearly varying thickness and attached to a winkler foundation," Journal of Sound and Vibration, vol. 144, no. 1, pp. 149-161, 1991.

[14] U. S. Gupta, R. Lal, and S. K. Jain, "Effect of elastic foundation on axisymmetric vibrations of polar orthotropic circular plates of variable thickness," Journal of Sound and Vibration, vol. 139, no. 3, pp. 503-513, 1990.

[15] A. H. Ansari and U. S. Gupta, "Effect of elastic foundation on asymmetric vibration of polar orthotropic parabolically tapered circular plate," Indian Journal of Pure and Applied Mathematics, vol. 30, no. 10, pp. 975-990, 1999.

[16] U. S. Gupta, A. H. Ansari, and S. Sharma, "Buckling and vibration of polar orthotropic circular plate resting on Winkler foundation," Journal of Sound and Vibration, vol. 297, no. 3-5, pp. 457-476, 2006.

[17] K. M. Liew, J.-B. Han, Z. M. Xiao, and H. Du, "Differential quadrature method for Mindlin plates on Winkler foundations," International Journal of Mechanical Sciences, vol. 38, no. 4, pp. 405-421, 1996.

[18] T. M. Wang and J. E. Stephens, "Natural frequencies of Timoshenko beams on pasternak foundations," Journal of Sound and Vibration, vol. 51, no. 2, pp. 149-155, 1977.

[19] B. Bhattacharya, "Free vibration of plates on Vlasov's foundation," Journal of Sound and Vibration, vol. 54, no. 3, pp. 464-467, 1977.

[20] A. K. Upadhyay, R. Pandey, and K. K. Shukla, "Nonlinear dynamic response of laminated composite plates subjected to pulse loading," Communications in Nonlinear Science and Numerical Simulation, vol. 16, no. 11, pp. 4530-4544, 2011.

[21] P. A. A. Laura, G. C. Pardoen, L. E. Luisoni, and D. Ávalos, "Transverse vibrations of axisymmetric polar orthotropic circular plates elastically restrained against rotation along the edges," Fibre Science and Technology, vol. 15, no. 1, pp. 65-77, 1981.

[22] D. J. Gunaratnam and A. P. Bhattacharya, "Transverse vibrations and stability of polar orthotropic circular plates: high-level relationships," Journal of Sound and Vibration, vol. 132, no. 3, pp. 383-392, 1989.

[23] G. N. Weisensel and A. L. Schlack Jr., "Annular plate response to circumferentially moving loads with sudden radial position changes," The International Journal of Analytical and Experimental Modal Analysis, vol. 5, no. 4, pp. 239-250, 1990.

[24] P. A. A. Laura, D. R. Avalos, and H. A. Larrondo, "Force vibrations of circular, stepped plates," Journal of Sound and Vibration, vol. 136, no. 1, pp. 146-150, 1990.

[25] G. C. Pardoen, "Asymmetric vibration and stability of circular plates," Computers and Structures, vol. 9, no. 1, pp. 89-95, 1978.

[26] P. A. A. Laura, C. Filipich, and R. D. Santos, "Static and dynamic behavior of circular plates of variable thickness elastically restrained along the edges," Journal of Sound and Vibration, vol. 52, no. 2, pp. 243-251, 1977.

[27] R. H. Gutierrez, E. Romanelli, and P. A. A. Laura, "Vibrations and elastic stability of thin circular plates with variable profile," Journal of Sound and Vibration, vol. 195, no. 3, pp. 391-399, 1996.

[28] B. Bhushan, G. Singh, and G. Venkateswara Rao, "Asymmetric buckling of layered orthotropic circular and annular plates of varying thickness using a computationally economic semianalytical finite element approach," Computers and Structures, vol. 59, no. 1, pp. 21-33, 1996.

[29] U. S. Gupta and A. H. Ansari, "Asymmetric vibrations and elastic stability of polar orthotropic circular plates of linearly varying profile," Journal of Sound and Vibration, vol. 215, no. 2, pp. 231-250, 1998.

[30] C. S. Kim and S. M. Dickinson, "The flexural vibration of thin isotropic and polar orthotropic annular and circular plates with elastically restrained peripheries," Journal of Sound and Vibration, vol. 143, no. 1, pp. 171-179, 1990.

[31] S. Sharma, R. Lal, and N. Singh, "Effect of non-homogeneity on asymmetric vibrations of non-uniform circular plates," Journal of Vibration and Control, 2015. 


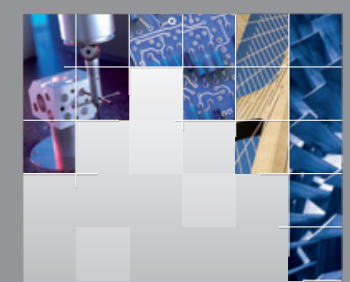

\section{Enfincering}
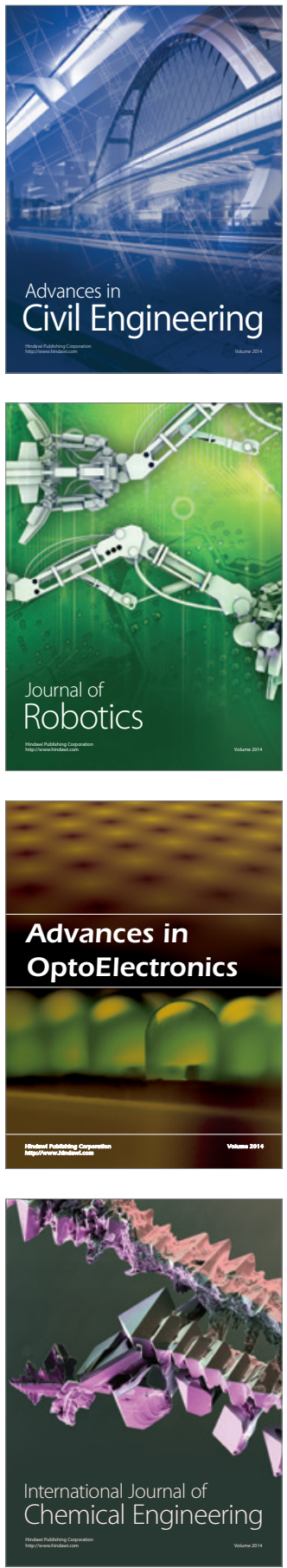

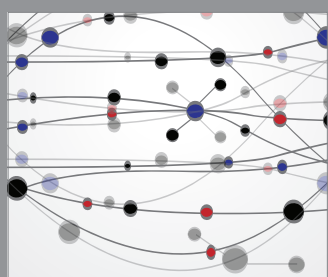

The Scientific World Journal

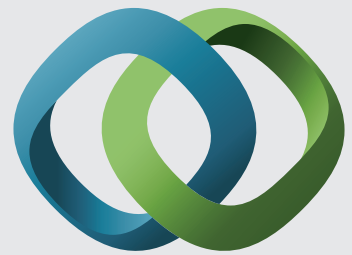

\section{Hindawi}

Submit your manuscripts at

http://www.hindawi.com
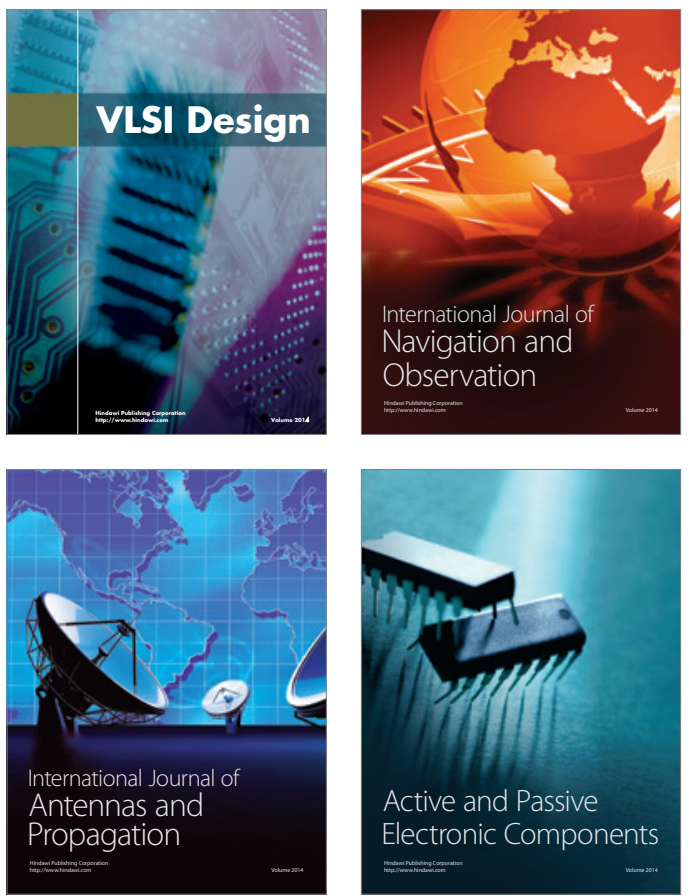
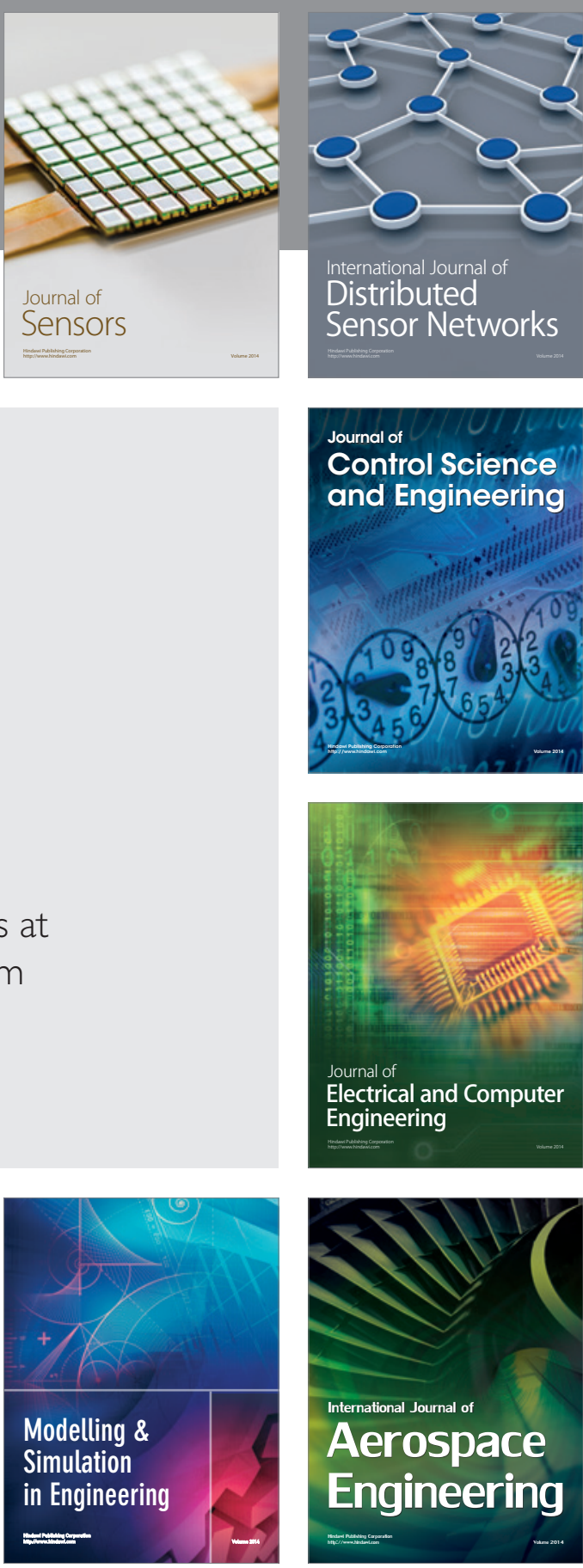

International Journal of

Distributed

Sensor Networks

Journal of

Control Science

and Engineering
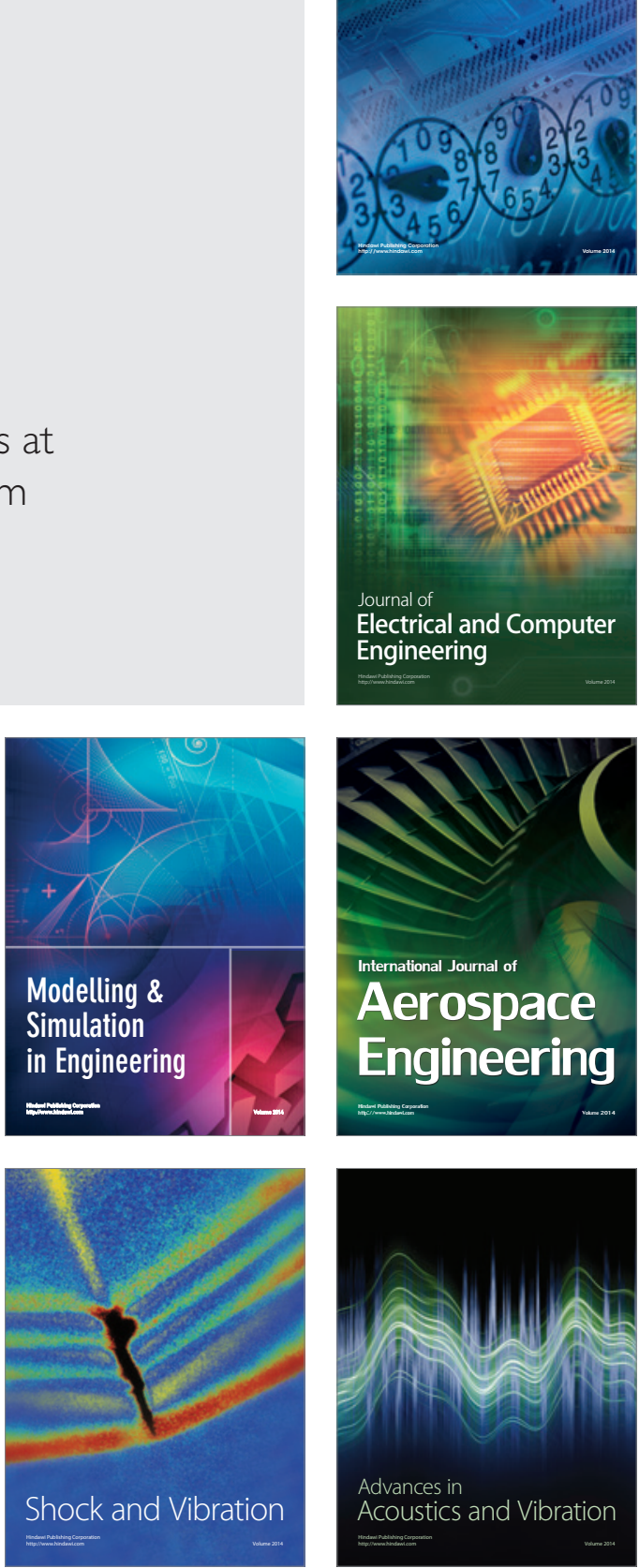